\title{
First report of a derived abelisaurid theropod from the Bajo de la Carpa Formation (Late Cretaceous), Patagonia, Argentina
}

\author{
MARTín DANIEL EZCURRA \& ARIEL HERNÁN MÉNDEZ
}

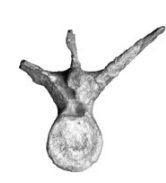

\begin{abstract}
An isolated anterior caudal vertebra of a medium-large sized theropod dinosaur is reported here. It comes from the Bajo de la Carpa Formation (Santonian, Late Cretaceous), Río Colorado Subgroup, Río Negro Province, northern Patagonia, Argentina. The specimen, MACN-PV-RN 1012, exhibits several derived characters that are diagnostic among theropods. Specifically, MACN-PV-RN 1012 is referable to Abelisauroidea because it possesses a centrodiapophyseal lamina on the ventral surface of the transverse processes, and to Abelisauridae due to the presence of transverse processes that are 1.4 times longer than the anteroposterior length of the centrum, a large median depression anterior to the base of the neural spine, and the lack of a prespinal fossa. MACN-PV-RN 1012 is included within Carnotaurinae, sharing with Carnotaurus and Aucasaurus transverse processes that are oriented dorsolaterally at an angle of $45^{\circ}$ or more with regard to the horizontal axis of the vertebra. Thus, the specimen described here constitutes the first record of a derived abelisaurid from the Bajo de la Carpa Formation. $•$ Key words: Theropoda, Abelisauroidea, Bajo de la Carpa Formation, Río Colorado Subgroup, Late Cretaceous, Argentina.
\end{abstract}

EZCURRA, M.D. \& MÉnDEZ, A.H. 2009. First report of a derived abelisaurid theropod from the Bajo de la Carpa Formation (Late Cretaceous), Patagonia, Argentina. Bulletin of Geosciences 84(3), 547-554 (3 figures). Czech Geological Survey, Prague. ISSN 1214-1119. Manuscript received November 4, 2008; accepted in revised form January 6, 2009; published online July 28, 2009; issued September 11, 2009.

\begin{abstract}
Martín Daniel Ezcurra (corresponding author), Laboratorio de Anatomía Comparada y Evolución de los Vertebrados, Museo Argentino de Ciencias Naturales "Bernardino Rivadavia”, Av. Ángel Gallardo 470, (1405), Buenos Aires, Argentina; martindezcurra@yahoo.com.ar • Ariel Hernán Méndez, Laboratorio de Anatomía Comparada y Evolución de los Vertebrados, Museo Argentino de Ciencias Naturales "Bernardino Rivadavia”, Av. Ángel Gallardo 470, (1405), Buenos Aires, Argentina. CONICET - Consejo Nacional de Investigaciones Científicas y Técnicas; arielhmendez@ yahoo.com.ar
\end{abstract}

\begin{abstract}
Abelisauroid theropods were one of the dominant groups of Gondwanan predatory dinosaurs during the Cretaceous. Abelisauroids are scarcely known from Jurassic and Early Cretaceous outcrops (Accarie et al. 1995, Allain et al. 2007, Bonaparte 1996, Rauhut 2005, Rauhut et al. 2003, Sereno \& Brusatte 2008); conversely they are well documented in the Late Cretaceous of Europe, South America, Africa, Madagascar and India (e.g., Bonaparte 1991, Allain \& Pereda-Suberbiola 2003, Sereno et al. 2004, Novas et al. 2004, Carrano \& Sampson 2008). In Patagonia remains of several abelisauroids have been exhumed in the last three decades, substantially increasing our knowledge of the clade (Bonaparte 1985; 1991a, b; 1996; Bonaparte \& Novas 1985; Bonaparte et al. 1990; Calvo et al. 2004; Canale et al. 2008; Coria 2001; Coria \& Salgado 2000; Coria et al. 2002, 2006; Juárez Valieri et al. 2007; Lamanna et al. 2002; Martínez et al. 1986, 2004).
\end{abstract}

Among the Late Cretaceous dinosaur bearing beds of Patagonia, one of the more prolific is the Bajo de la Carpa Formation, cropping out in the Río Negro and Neuquén Provinces of northwestern Patagonia (Bonaparte 1991b, Martinelli \& Vera 2007, Porfiri et al. 2008). Among the diverse tetrapod fauna of this sedimentary unit, which includes abundant notosuchian mesoeucrocodylians and snakes (Woodward 1896, 1901; Martinelli 2003; Pol 2005; Martinelli \& Pais 2008), five different small-sized theropod taxa have been described: the abelisauroid Velocisaurus unicus (Bonaparte 1991b), the alvarezsaurids Alvarezsaurus calvoi (Bonaparte 1991b) and Achillesaurus manazzonei (Martinelli \& Vera 2007), the enantiornithean Neuquenornis volans (Chiappe \& Calvo 1994), and the basal ornithuromorph Patagopteryx deferrariisi (Alvarenga \& Bonaparte 1992). Nevertheless, it was not until recently that a medium-sized tetanuran theropod was reported from the Bajo de la Capra Formation, in beds corresponding to the 


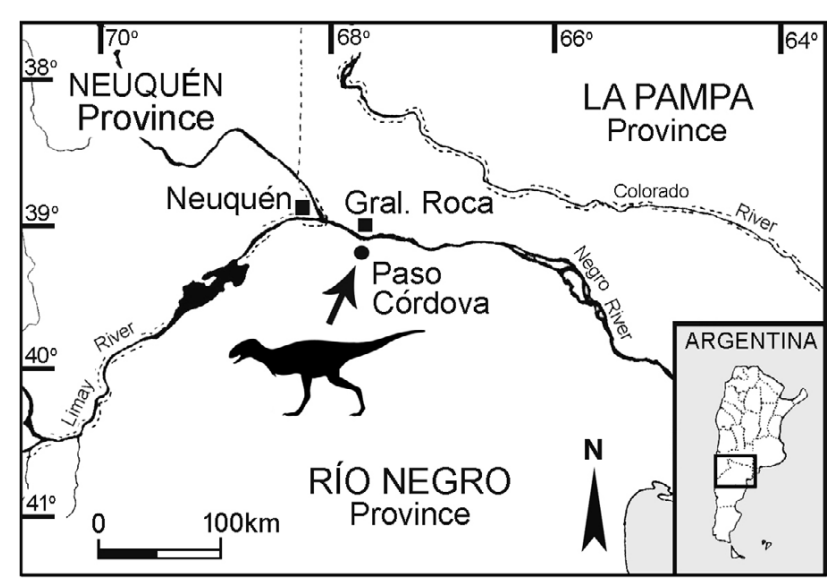

Figure 1. Map showing the Paso Córdova locality, Río Negro Province (Bajo de la Carpa Formation), northern Patagonia, Argentina that yielded the specimen MACN-PV-RN 1012. Modified from Martinelli \& Vera 2007.

Neuquén Province (Porfiri et al. 2008). In the present contribution, we describe abelisaurid theropod remains from this prolific Cretaceous Patagonian outcrop. These remains constitute the first evidence of a medium to large-sized abelisaurid theropod from this assemblage.

\section{Materials and methods}

Institutional abbreviations. - MACN-PV - Museo Argentino de Ciencias Naturales "B. Rivadavia", Paleontología de Vertebrados, Buenos Aires, Argentina (RN, colección Río Negro; CH, colección Chubut); MCF-PVPH - Museo Carmen Funes, Paleontología de Vertebrados de Plaza Huincul, Plaza Huincul, Argentina; MMCH-PV - Museo Municipal "Ernesto Bachmann”, Villa El Chocón, Neuquén, Argentina; MPEF-PV - Museo Paleontológico Egidio Feruglio, Paleontología de Vertebrados, Trelew, Argentina; MUCPv - Museo de la Universidad Nacional del Comahue, Paleontología de Vertebrados, Neuquén, Argentina; UCMP - University of California Museum of Paleontology, Berkeley, California, USA.

Systematic nomenclature. - We follow Rauhut (2003), Sereno et al. (2004) and Carrano \& Sampson (2008) regarding the phylogenetic relationships of Ceratosauria and Abelisauroidea within Theropoda; namely, that Coelophysoidea and Ceratosauria do not comprise a monophyletic group, and that the latter is more closely related to Tetanurae than is the former. Holtz's (1994) cladistic definition of Abelisauroidea is followed (i.e. the clade including all theropods closer to Carnotaurus sastrei than to Ceratosaurus nasicornis). Thus, following many previous cladistic analyses, Elaphrosaurus is considered here a basal abelisauroid (Rauhut 2003).

\section{Systematic paleontology}

Theropoda Marsh, 1881

Neotheropoda Bakker, 1986

Abelisauroidea Bonaparte, 1991

Abelisauridae Bonaparte \& Novas, 1985

Carnotaurinae Sereno, 1998

\section{Genus et species indet.}

Material. - MACN-PV-RN 1012, isolated anterior caudal vertebra.

Horizon and locality. - South bank of the Negro River, close to the city of General Roca, Paso Córdova locality, Río Negro Province, northern Patagonia, Argentina. Bajo de la Carpa Formation, Río Colorado Subgroup, Neuquén Group [Santonian, Late Cretaceous (Bonaparte 1996, Hugo \& Leanza 2001, Leanza et al. 2004)].

Description. - MACN-PV-RN 1012 consists of an isolated anterior caudal vertebra in a good state of preservation (Figs 2A-H, 3C). It lacks the distal half of the neural spine, the lateral end of the left transverse process, the prezygapophyses, and the anteroventral border of the centrum.

MACN-PV-RN 1012 does not correspond to the first caudal vertebra, because the transverse processes are not strongly posteriorly oriented and do not posteriorly surpass the posterior edge of the neural spine. Instead, the transversely laminar neural spine indicates that this vertebra could belong between the fourth and sixth positions in the caudal series.

On the left side, the centrum is fused to the neural arch without trace of suture, whereas a faint suture remains visible on the right side. This near-complete fusion of the neurocentral suture suggests that MACN-PV-RN 1012 does not correspond to a juvenile individual. The centrum is slightly constricted at mid-length (Fig. 2E). As observed in ventral view, the facets for articulation with the haemal arch are extended from the posterior end of the centrum towards its anteroposterior midline. The facets bound a shallow median depression.

The anterior and posterior articular facets of the centrum are circular in contour and concave, the anterior facet more deeply so (Fig. 2F, H). The shape of the articular facets closely resembles that of Carnotaurus (Bonaparte $e t$ al. 1990, MACN-PV-CH 894), Aucasaurus (Coria et al. 2002, MCF-PVPH 236) and Ilokelesia (Coria \& Salgado 2000, MCF-PVPH 35), but contrasts with Majungasaurus, in which these facets are elliptical (O'Connor 2007). The anterior articular facet is most deeply concave ventrally. Both facets are bounded by thick buttresses, but only the posterior buttress is completely preserved. On the posterior articular facet, the buttress is better developed towards the 

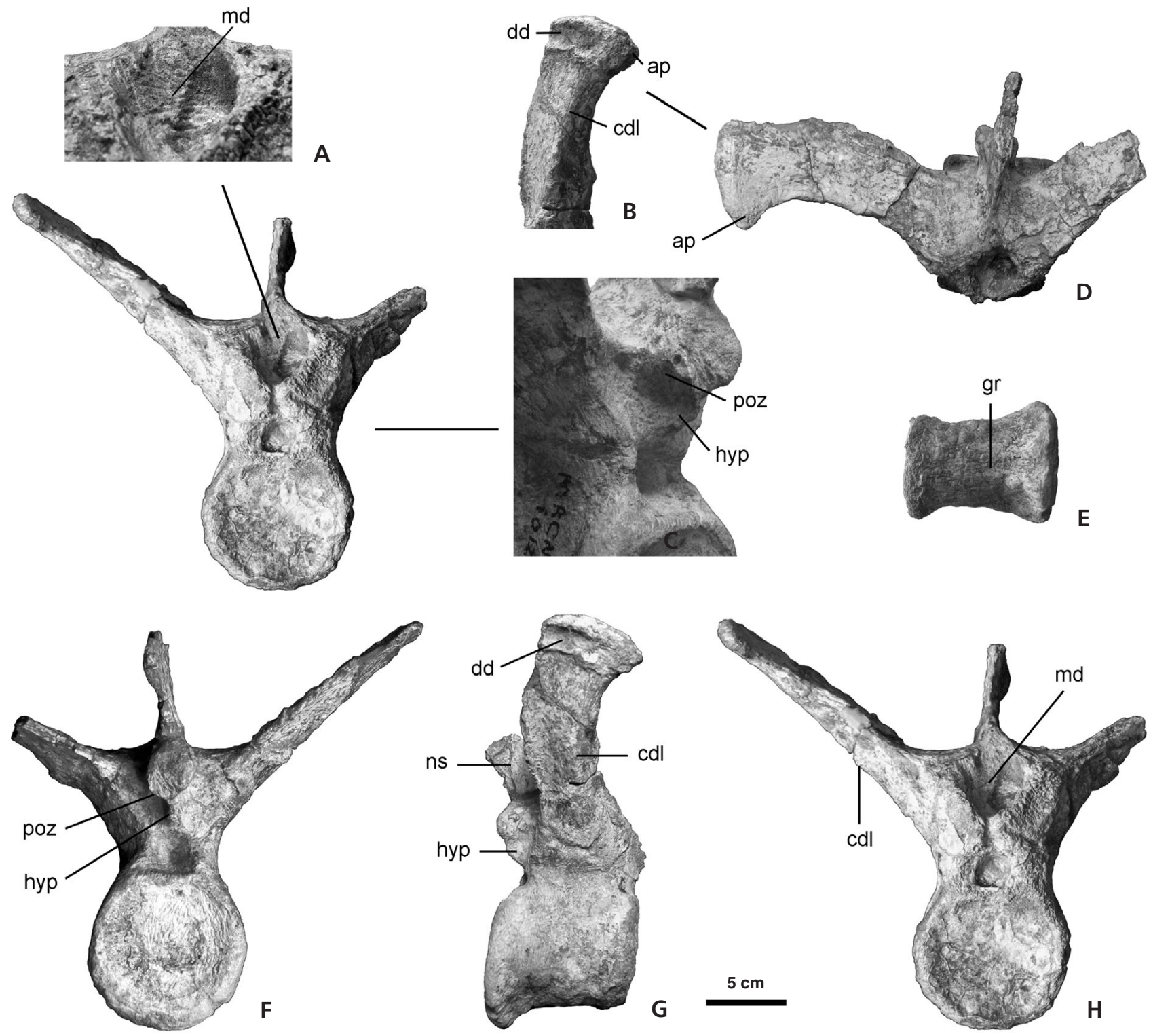

Figure 2. Detail of abelisauroid apomorphies recognized in the specimen MACN-PV-RN 1012: A - median depression in anterior view. $\bullet$ B - right transverse process in ventral view. $\bullet \mathrm{C}-$ neural arch in posterolateral view. $\bullet \mathrm{D}-\mathrm{H}-\mathrm{MACN}-\mathrm{PV}-\mathrm{RN} 1012$ in dorsal (D), ventral (E), posterior (F), anterior (G), and right lateral views (H). - Abbreviations: ap. - anterior projection, cdl. - centrodiapophyseal lamina, dd. - distal depression, gr. - groove, hyp. - hyposphene, md. - median depression, ns. - neural spine, poz. - postzygapophysis.

ventral portion of the centrum. Although it lacks the ventral portion of the anterior buttress, the centrum is ventrally concave. The lateral surface of the centrum does not exhibit any kind of depression or foramen.

Only the bases of the prezygapophyses are preserved, with a shallow, median vertical groove between them. As in Carnotaurus and Aucasaurus (Rauhut et al. 2003), a very large and deep fossa is present posterior to the prezygapophyses, being posterodorsally bounded by the spinoprezygapophyseal laminae. As seen in posterior view, the postzygapophyses are ventrolaterally oriented and somewhat damaged. Ventral to the postzygapophyses, a well devel- oped hyposphene is present (Fig. 2C, G), resembling the condition present in other basal theropods [e.g., Lophostropheus (Ezcurra \& Cuny 2007), Dilophosaurus (Welles 1984), UCMP 37302; Ceratosaurus (Madsen \& Welles 2000), Aucasaurus (Coria et al. 2002), Carnotaurus (Bonaparte et al. 1990), MACN-PV-CH 894; Condorraptor, MPEF-PV 1682; Monolophosaurus (Currie \& Zhao 1993)].

The right transverse process is nearly complete, lacking only parts of the anterior and posterior projections at its lateral extreme. Only the medial half of the left transverse process is preserved. In dorsal view, the transverse process shows a concave anterior border and a convex posterior 
margin (Fig. 2D), which is gently anteriorly curved towards its lateral tip. The transverse process is posterolaterodorsally projected at an angle of about 50 degrees to the horizontal, resembling the condition in Carnotaurus (Bonaparte et al. 1990, MACN-PV-CH 894), Aucasaurus (Coria et al. 2002, MCF-PVPH 236) and Masiakasaurus (Carrano et al., 2002), but contrasting with the lower angle present in Majungasaurus (approximately 20 degrees) (O’Connor 2007), Ilokelesia (Coria \& Salgado 2000, MCF-PVPH 35), Ekrixinatosaurus (Calvo et al. 2004, MUCPv 294) and Skorpiovenator (Canale et al. 2008). The dorsal surface of the transverse process is almost flat. As is the case in Majungasaurus (O'Connor 2007), Ekrixinatosaurus (Calvo et al. 2004) and Carnotaurus (MACN-PV-CH 894), a thick lamina is present along the ventral surface of most of the transverse process. A shallow, wide concavity is present posterior to this ventral lamina. At the medial base of the transverse process, an elliptical fossa is present on the anterior surface, being ventrally bounded by the centrodiapophyseal lamina and a prominent ridge dorsally. The lateral tip of the transverse process exhibits a well-developed anterior projection. A conspicuous parasagittal ridge is present on the ventral surface of the lateral tip. This feature is also present in the abelisaurids Ekrixinatosaurus (MUCPv 294), Aucasaurus (MCF-PVPH 236) and Carnotaurus (MACN-PV-CH 894). This ridge medially delimits a well-defined fossa that extends to the lateral end of the transverse process (Fig. 2B, G). The lateral margin of the process is rounded in dorsal view.

The neural spine is represented only by its ventral half, rendering it impossible to discern if the spine was "L"-shaped as in Carnotaurus (Bonaparte et al. 1990). As in other abelisaurids, the neural spine is posterodorsally oriented and transversely narrow, with a very sharp anterior margin that lacks a prespinal fossa. The neural spine extends anteroposteriorly along the posterior $3 / 4$ of the length of the centrum.

\section{Discussion - Phylogenetic relationships of MACN-PV-RN 1012}

Previous authors have recognized several apomorphies in the anterior caudal vertebrae of abelisauroids (Bonaparte 1991a, Bonaparte et al. 1990, Coria \& Salgado 2000, Coria et al. 2002, Rauhut et al. 2003). MACN-PV-RN 1012 exhibits several of these characters. Derived features of Abelisauroidea and less inclusive clades recognized in the Bajo de la Carpa vertebra are discussed below.

Presence of centrodiapophyseal laminae in anterior and anterior-middle caudals (Rauhut et al. 2003). - Rauhut et al. (2003) regarded the presence of centrodiapophyseal laminae in anterior caudals as an apomorphy shared by several members of Abelisauroidea (e.g., Carnotaurus, Aucasaurus, and an abelisaurid theropod from the La Paloma Member of the Cerro Barcino Formation, hereafter referred to as the "La Paloma abelisaurid"). Rauhut et al. (2003) also stated that the condition in the abelisaurids Ilokelesia and Abelisaurus was uncertain. Nevertheless, the basal abelisaurids Ekrixinatosaurus (Calvo et al. 2004) and Majungasaurus (O’Connor 2007) also presents centrodiapophyseal laminae on the ventral surface of the transverse processes. Since Rauhut et al. (2003) considered this lamina to be absent in non-abelisauroid theropods (e.g., Ceratosaurus, Allosaurus), this feature seems to be restricted to Abelisauroidea. Accordingly, the presence of a well- developed centrodiapophyseal lamina in MACN-PV-RN 1012 supports the assignment of the specimen to Abelisauroidea (Fig. 2B).

Transverse processes more than 1.4 times the length of the anterior caudal vertebral centrum (Rauhut et al. 2003). Rauhut et al. (2003) provided a detailed discussion of the distribution of this feature within Neotheropoda. Short transverse processes are present in non-averostran theropods [e.g., Liliensternus (Huene 1934), Dilophosaurus (Welles 1984; UCMP 37302), Allosaurus (Madsen 1976), Sinraptor (Currie \& Zhao 1993)], as well as in the basal ceratosaurians Ceratosaurus (Madsen \& Welles 2000) and Masiakasaurus (Carrano et al. 2003). On the other hand, as pointed out by Rauhut et al. (2003), the derived condition of strongly elongated transverse processes (more than 1.4 times longer than the anteroposterior length of the centrum) is present in the La Paloma abelisaurid and the abelisaurids Carnotaurus and Aucasaurus, as well as in the abelisaurids Majungasaurus (O'Connor 2007), Skorpiovenator (MMCH-PV 48) and Ekrixinatosaurus (MUCPV 294). In this context, we agree with Rauhut et al. (2003) in considering this character as probably synapomorphic of Abelisauridae. The derived condition is also present in MACN-PV-RN 1012 (Fig. 2D), supporting the assignment of this specimen to that clade.

Presence of a parasagittal ridge on the ventrolateral end of the transverse processes of anterior caudal vertebrae. The ventral surface of the lateral end of the right transverse process of MACN-PV-RN 1012 presents an anteroposteriorly concave and very smooth depression that is delimited medially by a sharp ventromedial ridge. This ridge is also present in the abelisaurids Ekrixinatosaurus (MUCPv 294), Aucasaurus (MCF-PVPH 236) and Carnotaurus (MACN-PV-CH 894). Nevertheless, this ridge is absent in basal neotheropods and more basal ceratosaurians, such as the available caudals of Dilophosaurus (UCMP 37302) and Ceratosaurus (Madsen \& Welles 2000). Thus, this character seems to constitute an apomorphy shared by $E k$ rixinatosaurus and carnotaurinins. 

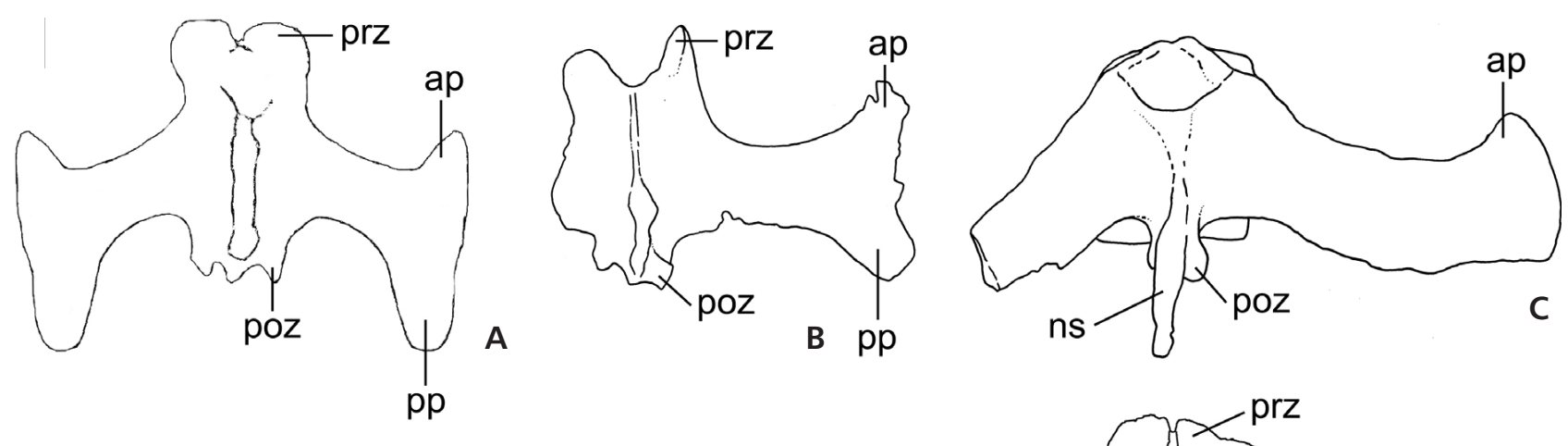
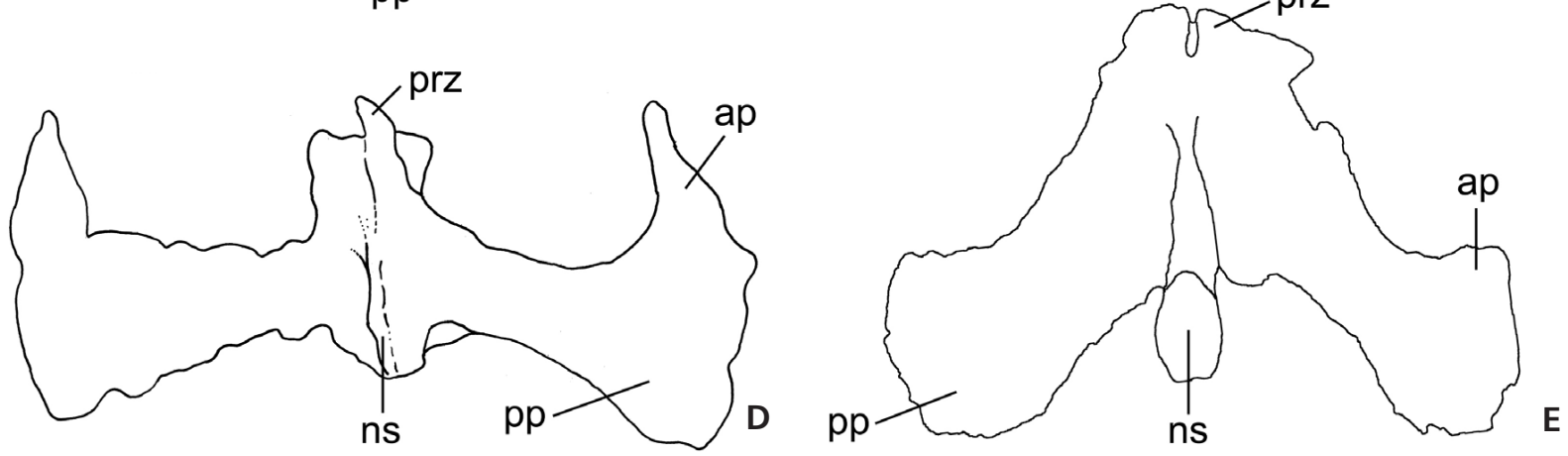

Figure 3. Line drawings of several abelisauroid anterior and mid-caudal vertebrae in dorsal view: • A - Ekrixinatosaurus novasi (MUCPv 294). - B - Ilokelesia aguadagrandensis (MCF-PVPH-35). • C - MACN-PV-RN 1012. • D - Aucasaurus garridoi (MCF-PVPH-236). • E - Carnotaurus sastrei (MACN-PV-CH 894). - Abbreviations: ap. - anterior projection, cdl. - centrodiapophyseal lamina, dd. - distal depression, hyp. - hyposphene, md. - median depression, ns. - neural spine, poz. - postzygapophysis, pp. - posterior projection, prz. - prezygapophysis. (A - after Calvo et al. 2004; B - after Coria \& Salgado 2000).

In the anterior-most caudals (i.e., C1-3) of Aucasaurus (MCF-PVPH 236), Carnotaurus (MACN-PV-CH 894) and Ekrixinatosaurus (MUCPv 294), the ventral ridge is positioned close to the mid-length of the transverse processes. In Carnotaurus, the ridge disappears posterior to the fourth caudal, whereas in Aucasaurus the ridge continues along most of the anterior caudal series but migrates laterally towards the tip of the tail (MCF-PVPH 236). In MACN-PV-RN 1012, the ventrolateral ridge is close to the lateral tip of the transverse process, resembling the condition in caudals 4 and 5 of Aucasaurus (MCF-PVPH 236).

Due to the absence of rugosities, the ventrolateral depression which is medially delimited by this ridge does not seem to correspond to the attachment area of a tendon. This depression may instead correspond to a muscle attachment area, but its surface is very smooth, providing evidence against this hypothesis as well. Following the descriptions of Coria et al. (2002) for Aucasaurus, and Canale et al. (2008) for Skorpiovenator, another possibility is that this depression received the anterior projection of the transverse process of the subsequent caudal vertebra, as a result of an overlapping articulation between these processes. However, because MACN-PV-RN 1012 consists of only a single caudal vertebra, this kind of accessory articulation cannot be ascertained for this specimen; moreover, in other taxa which exhibit the ventrolateral ridge and fossa (e.g., Ekrixinatosaurus and Carnotaurus) no evidence of over- lapping transverse processes was observed (MUCPv 294, MACN-PV-CH 894). The latter observation weakens the hypothesis that this parasagittal ridge and fossa participated in an osseous intervertebral interlocking of transverse processes, at least in Ekrixinatosaurus and Carnotaurus, contrasting with Aucasaurus and Skorpiovenator (Coria et al. 2002, Canale et al. 2008).

Large median depression anterior to the ventral base of the neural spine and absence of prespinal fossa in anterior caudal vertebrae (Coria \& Salgado 2000, Rauhut et al. 2003). Rauhut et al. (2003) reported that Carnotaurus, Majungasaurus, and the La Paloma abelisaurid exhibit a wide and deep median depression posterior to the prezygapophyses, and that no prespinal fossa is present at the anterior base of the neural spine. On the other hand, the vast majority of theropods, including the non-abelisaurid ceratosaurians Ceratosaurus (Madsen \& Welles 2000), Elaphrosaurus (Rauhut et al. 2003), and Masiakasaurus (Carrano et al. 2002), lack this deep and wide median depression posterior to the prezygapophyses, and present a prespinal fossa at the base of the neural spine. Therefore this feature seems to be restricted to Abelisauridae, and MACN-PV-RN 1012 presents the apomorphic condition of the character (Fig. 2A).

Transverse processes oriented at an angle of $45^{\circ}$ or more with respect to the horizontal axis of anterior caudal verteb- 
rae (modified from Bonaparte et al. 1990). - In Theropoda ancestrally (e.g., Liliensternus, Dilophosaurus, Ceratosaurus, Allosaurus, Sinraptor, Huene 1934, Welles 1984, Madsen \& Welles 2000, Madsen 1976, Currie \& Zhao 1993), the transverse processes are horizontally projected in anterior caudal vertebrae. Within Abelisauroidea, the latter condition is retained in Elaphrosaurus. In Majungasaurus (O'Connor 2007), Ekrixinatosaurus (MUCPv 294) and Skorpiovenator (Canale et al. 2008), the transverse processes are almost horizontally oriented, being only gently dorsally projected. On the other hand, in Carnotaurus (MACN-PV-CH 894), Aucasaurus (MCF-PVPH 236) and MACN-PV-RN 1012, the transverse processes of the anterior caudals are dorsolaterally oriented at an angle of $45^{\circ}$ or more with respect to the transverse axis of the vertebra (Fig. 2F, H).

Presence of well developed hyposphene in anterior and mid-caudal vertebrae (Coria et al. 2002). - The presence of hyposphene-hypantrum articulations in anterior and mid-caudal vertebrae was proposed by Coria et al. (2002) as a synapomorphy shared by the carnotaurinins Carnotaurus and Aucasaurus. However, such articulations are also present in the anterior caudals of non-averostran theropods [e.g., Lophostropheus (Ezcurra \& Cuny 2007), Dilophosaurus (Welles 1984)], tetanurans [e.g., Condorraptor (MPEF-PV 1682), Monolophosaurus (Zhao \& Currie 1993), Sinraptor (Currie \& Zhao 1993)] and the basal ceratosaurian Ceratosaurus (Madsen \& Welles 2000). In Majungasaurus, hyposphene-hypantrum articulations are only incipient (O'Connor 2007), whereas anterior and midcaudals are not available for the basal abelisauroids Ligabueino and Noasaurus. Coria \& Salgado (2000) reported that the mid-caudals of Ilokelesia lack hyposphene-hypantrum articulations, thus contrasting with Aucasaurus and Carnotaurus. However, the presence or absence of these structures in anterior caudals of the former taxon is unknown. Accordingly, the distribution of this feature within Abelisauroidea is not currently clear. Thus, we follow Rauhut et al. (2003) in considering the presence of hyposphene-hypantrum articulations in anterior caudals as a probable symplesiomorphy of Neotheropoda. In this context, the anterior caudal reported here (MACN-PV-RN 1012) resembles Carnotaurus and Aucasaurus, as well as other basal neotheropods, in possessing a well-developed hyposphene-hypantrum (Fig. 2C). Although the presence of this structure in the Bajo de la Carpa vertebra does not preclude its referral to Abelisauroidea or clades within, it cannot be considered as definitive evidence for this referral.

In summary, based on the discussion of the above apomorphies, we can assign MACN-PV-RN 1012 to Abelisauroidea due to the presence in this specimen of 1) transverse processes with a centrodiapophyseal lamina (Rauhut et al. 2003). Furthermore, MACN-PV-RN 1012 can be assigned to Abelisauridae due to the presence of 2) transverse processes more than 1.4 times the anteroposterior length of the vertebral centrum (Rauhut et al. 2003), 3) a large median depression anterior to the ventral base of the neural spine and the absence of a prespinal fossa (Coria \& Salgado 2000, Rauhut et al. 2003) and 4) a ventrolaterally-positioned parasagittal ridge on the lateral end of the transverse process of the anterior caudal vertebrae. Finally, MACN-PV-RN 1012 seems to be more derived than Ilokelesia, Ekrixinatosaurus, Skorpiovenator, and Majungasaurus in that it shares with Carnotaurus and Aucasaurus 5) transverse processes oriented at an angle of $45^{\circ}$ or more with regard to the horizontal axis of the anterior caudal vertebrae (modified from Bonaparte et al. 1990). In agreement with the latter assertion, MACN-PV-RN 1012 resembles Carnotaurus and Aucasaurus in possessing a well-developed hyposphene in the anterior caudal vertebrae (Coria et al. 2002), but the distribution of hyposphene-hypantrum articulations among abelisauroids is currently problematic (Rauhut et al. 2003; see above). Character 5 supports the assignment of MACN-PV-RN 1012 to the abelisauroid clade Carnotaurinae. Furthermore, at the moment, this character is shared only by MACN-PV-RN 1012 and Carnotaurini (i.e., Carnotaurus and Aucasaurus). However, the specimen reported here cannot currently be included within the latter clade due to the node-based definition of the group (Coria et al. 2002) and the uncertain phylogenetic position of MACN-PV-RN-1012 relative to Aucasaurus and Carnotaurus. In this context, MACN-PV-RN 1012 is interpreted here as Carnotaurinae indet.

As was mentioned in the description, the transverse processes of MACN-PV-RN 1012 present concave and convex anterior and posterior borders, respectively. The convex posterior border differs from that of other abelisauroids, in which this border is concave or straight (e.g., Ekrixinatosaurus, Carnotaurus, Aucasaurus, Ilokelesia; MUCPv 294, MACN-PV-CH 894, MCF-PVPH 236, MCF-PVPH 35). Thus, the transverse processes of MACN-PV-RN 1012 exhibit a distinct but gentle anterior curvature. However, the fragmentary nature of MACN-PV-RN 1012 does not warrant erecting a new taxon without more available data.

The lateral end of the right transverse process of the Bajo de la Carpa vertebra is damaged, preserving only the base of the well-developed anterior projection. The lateral expansion of the transverse process resembles that of other abelisauroids. Previous authors (Calvo et al. 2004, Coria \& Salgado 2000, Coria et al. 2002) have recognized only a single apomorphic state for the lateral expansion of the transverse processes. Nevertheless, among basal abelisauroids, the lateral end of the transverse processes present anterior and posterior projections that are strongly and equally developed (e.g., Ilokelesia, Skorpiovenator; Coria \& Salgado 2000; MMCH-PV 48), or the posterior projection is more 
strongly developed (e.g., Ekrixinatosaurus; Calvo et al. 2004) (Fig. 3A, B). On the other hand, in more derived forms such as Carnotaurus (MACN-PV-CH 894) and Aucasaurus (MCF-PVPH 236), the anterior projection is more developed than the posterior one (Fig. 3D, E). As preserved, the lateral end of the right transverse process of MACN-PV-RN 1012 suggests that the condition it represents would be similar to that of Carnotaurus and Aucasaurus, but this interpretation is tentative (Fig. 3C). This latter morphology could also support the assignment of specimen MACN-PV-RN 1012 to a derived position within Abelisauroidea.

\section{Conclusion}

In the present contribution an isolated anterior caudal vertebra recovered from the Santonian Bajo de la Carpa Formation at the Paso Córdova locality (Río Negro Province, Argentina) is described. The specimen is interpreted as a medium-large-sized carnotaurin abelisaurid. This assignment indicates that specimen MACN-PV-RN 1012 represents a taxon distinct from Velocisaurus (Bonaparte 1991b), the unique abelisauroid hitherto reported from the Bajo de la Carpa Formation. Accordingly, the theropodan fauna of this sedimentary unit is represented by several small-sized theropods, as well as the medium-sized abelisaurid reported here and a basal tetanuran (Porfiri et al. 2008). MACN-PV-RN 1012 also exhibits deep ventrolateral depressions on the transverse processes, but it was demonstrated that they are not directly associated with the presence of osseous interlocking articulations between the transverse processes of adjacent anterior caudal vertebrae, at least in the Bajo de la Carpa abelisaurid, Carnotaurus, and Ekrixinatosaurus.

\section{Acknowledgments}

We thank J.F. Bonaparte who allowed us to study this specimen. A. Kramarz, E. Ruigomez, J. Porfiri, P. Holroyd, J. Canale and L. Rickemberg provided access to material under their care. A. Martinelli provided useful data about the material reported here and Fig. 1. E. López Rolandi kindly drew the abelisauroid silhouette in Fig. 1. L. Salgado made some comments and suggestions on an early version of the manuscript. A. Marinelli and M. Lamanna provided useful comments which improved the quality of the paper. Lastly, we are grateful to J. Canale for his comments on abelisauroid caudal anatomy and photographs of the tails of these theropods.

\section{References}

ACCARIE, H., BeAudoin, B., DejaX, J., Fries, G., Michard, J.-G. \& TAQUET, P. 1995. Découverte d'un dinosaure théropode nouveau (Genusaurus sisteronis n. g., n. sp.) dans l'albien marin de sisteron (Alpes de Haute-Provence, France) et exten- sion au Crétacé inférieur de la lignée cératosaurienne. Comptes rendus de l'Académie de sciences 320, 327-334.

Allain, R. \& Pereda Suberbiola, X. 2003. Dinosaurs of France. Comptes Rendus Palevol 2, 27-44.

DOI 10.1016/S1631-0683(03)00002-2

Allain, R., Tykoski, R.S., Aquesbi, N., Jalil, N.-E., MonBARON, M., RUSSELL, D. \& TAQUET, P. 2007. An abelisauroid (Dinosauria: Theropoda) from the Early Jurassic of the High Atlas Mountains, Morocco, and the radiation of ceratosaurs. Journal of Vertebrate Paleontology 27, 610-624. DO] 10.1671/0272-4634(2007)27[610:AADTFT]2.0.CO;2

ALVARENGA, H.M.F. \& BONAPARTE, J.F. 1992. A new flightless land-bird from the Cretaceous of Patagonia. In CAMPBELL, K.E. (ed.) Papers in Avian Paleontology. Natural History Museum of Los Angeles County, Science Series 36, 51-64.

BONAPARTE, J.F. 1985. A horned Cretaceous carnosaur from Patagonia. National Geographic Research 1, 149-151.

BONAPARTE, J.F. 1991a. The Gondwanian theropod families Abelisauridae and Noasauridae. Historical Biology 5, 1-25. DOI 10.1080/10292389109380385

BONAPARTE, J.F. 1991b. Los vertebrados fósiles de la Formación Río Colorado, de la Ciudad de Neuquén y cercanías, Cretácico superior, Argentina. Revista del Museo Argentino de Ciencias Naturales "Bernardino Rivadavia”. Paleontología 4(3), 17-123.

BONAPARTE, J.F. 1996. Cretaceous tetrapods of Argentina. Münchner Geowissenschaftliche Abhandlungen A 30, 73-130.

BONAPARTE, J.F. \& NOVAS, F.E. 1985. Abelisaurus comahuensis, n. gen., n. sp., Carnosauria del Cretácico Tardío de Patagonia. Ameghiniana 21, 259-265.

BONAPARTe, J.F., NOVAS, F.E. \& CORIA, R.A. 1990. Carnotaurus sastrei Bonaparte, the horned, lightly built carnosaur from the middle Cretaceous of Patagonia. Contributions in Science, Natural History Museum of Los Angeles County 416, 1-41.

CAlvo, J.O., Rubilar-Rogers, D. \& Moreno, K. 2004. A new Abelisauridae (Dinosauria: Theropoda) from northwest Patagonia. Ameghiniana 41, 555-564.

Canale, J.I., Scanferla, C.A., Agnolin, F.L. \& Novas, F.E. 2008. New carnivorous dinosaur from the Late Cretaceous of NW Patagonia and the evolution of abelisaurid theropods. Naturwissenschaften. DOI 10.1007/s00114-008-0487-4

CARrano, M.T., SAMPSON, S.D. \& Forster, C.A. 2002. The osteology of Masiakasaurus knopfleri, a small abelisauroid (Dinosauria: Theropoda) from the Late Cretaceous of Madagascar. Journal of Vertebrate Paleontology 22, 510-534. DO] 10.1671/0272-4634(2002)022[0510:TOOMKA]2.0.CO;2

CARRANO, M.T. \& SAMPSON, S.D. 2008. The phylogeny of Ceratosauria (Dinosauria: Theropoda). Journal of Systematic Palaeontology 6, 183-236. DOI $10.1017 / \mathrm{S} 1477201907002246$

CHIAPPE, L.M. \& CALVO, J.O. 1994. Neuquenornis volans, a new Late Cretaceous bird (Enantiornithes: Avisauridae) from Patagonia, Argentina. Journal of Vertebrate Paleontology 14, 230-246.

CORIA, R.A. 2001. New theropod from the Late Cretaceous of Patagonia, 3-9. In TANKE, D.H. \& CARPENTER, K. (eds) Mesozoic vertebrate life. Indiana University Press, Bloomington. 
CORIA, R.A., CHIAPPE, L.M. \& DingUS, L. 2002. A new close relative of Carnotaurus sastrei Bonaparte 1985 (Theropoda: Abelisauridae) from the Late Cretaceous of Patagonia. Journal of Vertebrate Paleontology 22, 460-465. DO] 10.1671/0272-4634(2002)022[0460:ANCROC]2.0.CO;2

Coria, R.A., CurRie, P.J. \& CARABAJal, A.P. 2006. A new abelisauroid theropod from Northwestern Patagonia. Canadian Journal of Earth Sciences 43, 1283-1289.

\section{DOI 10.1139/E06-025}

CORIA, R.A. \& SAlgado, L. 2000. A basal Abelisauria, Novas 1992 (Theropoda-Ceratosauria) from the Cretaceous of Patagonia. Gaia 15, 89-102.

CURRIE, P.J. \& ZHAO, X. 1993. A new carnosaur (Dinosauria, Theropoda) from the Jurassic of Xinjiang, People's Republic of China. Canadian Journal of Earth Sciences 30, 2037-2081.

EZCURRA, M.D. \& CUNY, G. 2007. The coelophysoid Lophostropheus airelensis, nov. gen.: a review of the systematics of "Liliensternus" airelensis from the Triassic-Jurassic outcrops of Normandy (France). Journal of Vertebrate Paleontology 27, 73-86.

DOI 10.1671/0272-4634(2007)27[73:TCLAGN]2.0.CO;2

HOLTZ, T.R. JR. 1994. The phylogenetic position of the Tyrannosauridae: implications for theropod systematics. Journal of $\mathrm{Pa}$ leontology 68, 1100-1117.

HuENE, F. 1934. Ein neuer Coelurosaurier in der thuringischen Trias. Paläontologische Zeitschrift 16, 145-170.

HugO, C.A. \& LEANZA, H.A. 2001. Hoja Geológica 3969-IV, General Roca, provincias del Neuquén y Río Negro. Instituto de Geología y Recursos Naturales, Segemar, Boletín 308, 1-71.

JuÁrez VAlieri, R.D., Fiorelli, L.E. \& CRUZ, L.E. 2007. Quilmesaurus curriei Coria, 2001 (Dinosauria, Theropoda). Su validez taxonómica y relaciones filogenéticas. Revista del Museo Argentino de Ciencias Naturales, n.s. 9, 59-66.

LAMANNA, M.C., MARTÍNEZ, R.D. \& SMITH, J.B. 2002. A definitive abelisaurid theropod dinosaur from the early Late Cretaceous of Patagonia. Journal of Vertebrate Paleontology 22, 58-69. DOI 10.1671/0272-4634(2002)022[0058:ADATDF]2.0.CO;2

LEANZA, H.A., APESTEGUíA, S., Novas, F.E. \& DE LA FuENTE, M.S. 2004. Cretaceous terrestrial beds from the Neuquén Basin (Argentina) and their tetrapod assemblages. Cretaceous Research 25, 61-87. DOI 10.1016/j.cretres.2003.10.005

MADSEN, J.H. JR. 1976. Allosaurus fragilis: a revised osteology. Utah Geological Survey Bulletin 109, 1-163.

MAdSEN, J.H. JR. \& WelleS, S.P. 2000. Ceratosaurus (Dinosauria, Theropoda) a revised osteology. Utah Geological Survey Miscellaneous Publication 00-2, 1-80.

MARTINELLI, A.G. 2003. New cranial remains of the bizarre notosuchid Comahuesuchus brachybuccalis (Archosauria, Crocodyliformes) from the Late Cretaceous of Río Negro Province (Argentina). Ameghiniana 40, 559-572.

MARTINELLI, A.G. \& PAIS, D.F. 2008. A new baurusuchid crocodyliform (Archosauria) from the Late Cretaceous of Patagonia (Argentina). Comptes Rendus Palevol 7, 371-381. DOI 10.1016/j.crpv.2008.05.002

MARTINELLI, A.G. \& VERA, E.I. 2007. Achillesaurus manazzonei, a new alvarezsaurid theropod (Dinosauria) from the Late
Cretaceous Bajo de la Carpa Formation, Río Negro Province, Argentina. Zootaxa 1582, 1-17.

MARTíneZ, R., GimÉNEZ, O., RodRígueZ, J. \& BOCHATEy, G. 1986. Xenotarsosaurus bonapartei nov. gen. et sp. (Carnosauria, Abelisauridae), un nuevo Theropoda de la Formacion Bajo Barreal, Chubut, Argentina. Simposio de evolución de los vertebrados mesozoicos: IV Congreso Argentino de Paleontologia y Bioestratigrafía, 23-31.

MartíneZ, R., Novas, F.E. \& AMBrosio, A. 2004. Abelisaurid remains (Theropoda, Ceratosauria) from Southern Patagonia. Ameghiniana 41, 577-585.

O'CONNOR, P.M. 2007. The postcranial axial skeleton of Majungasaurus crenatissimus (Theropoda: Abelisauridae) from the Late Cretaceous of Madagascar, 127-162. In SAMPSON, S.D. \& KRAUSE, D.W. (eds) Majungasaurus crenatissimus (Theropoda: Abelisauridae) from the Late Cretaceous of Madagascar. Society of Vertebrate Paleontology Memoir 8.

POL, D. 2005. Postcranial remains of Notosuchus terrestris Woodward (Archosauria: Crocodyliformes) from the Upper Cretaceous of Patagonia, Argentina. Ameghiniana 42, 21-38.

PORFIRI, J.D, CALVO, J.O, JuÁREZ-VALIERI, R.D. \& SANTOS, D.D. 2008. A new large theropod dinosaur from the Bajo de la Carpa Formation (Late Cretaceous) of Neuquén, Patagonia. III Congreso Latinoamericano de Paleontologia de Vertebrados, 202.

RAUHUT, O.W.M. 2003. The interrelationships and evolution of basal theropod dinosaurs. Special Papers in Palaeontology 69, $1-214$.

RAUHUT, O.W.M. 2005. Post-cranial remains of 'coelurosaurs' (Dinosauria, Theropoda) from the Late Jurassic of Tanzania. Geological Magazine 142, 97-107. DOI $10.1017 / \mathrm{S} 0016756804000330$

Rauhut, O.W.M., Cladera, G., VicKers-Rich, P. \& Rich, T.H. 2003. Dinosaur remains from the Lower Cretaceous of the Chubut Group, Argentina. Cretaceous Research 24, 487-497. DOI $10.1016 / \mathrm{S} 0195-6671(03) 00067-3$

SERENO, P.C., Wilson, J.A. \& CONRAD, J.L. 2004. New dinosaurs link southern landmasses in the mid-Cretaceous. Proceedings of the Royal Society of London B, 1-6.

SERENO, P.C. \& BRUSATTE, S.L. 2008. Basal abelisaurid and carcharodontosaurid theropods from the Lower Cretaceous Elrhaz Formation of Niger. Acta Palaeontologica Polonica 53, $15-46$.

WELLES, S.P. 1984. Dilophosaurus wetherilli (Dinosauria, Theropoda): osteology and comparisons. Palaeontographica, Abteilung A 185, 85-180.

WoOdwARD, A.S. 1896. On two Mesozoic crocodilians Notosuchus (genus novum) and Cynodontosuchus (genus novum) from the red sandstones of the territory of Neuquén (Argentina Republic). Annales del Museo de La Plata, Paleontologia 4, $1-20$.

WoOdWARD, A.S. 1901. On some extinct reptiles from Patagonia of the genera Miolania, Dinilysia and Genyodectes. Proceedings of the Zoological Society of London 1901, 169-184.

ZHAO, X. \& CURRIE, P.J. 1993. A large crested theropod from the Jurassic of Xinjiang, People's Republic of China. Canadian Journal of Earth Sciences 30, 2027-2036. 